DOI: 10.5902/19834659 15510

\title{
PROGRAMAS DE BENEFÍCIOS SOCIAIS PARA PROFISSIONAIS BRASILEIROS COMO FORMA DE RETER TALENTOS: UM ESTUDO EXPLORATÓRIO
}

\author{
Data de submissão: 12/09/2014 \\ Aceite: 26/05/2016 \\ José Alberto Carvalho dos Santos Claro ${ }^{1}$ \\ Rogério Augusto Profeta²
}

\section{RESUMO}

O presente estudo teve como objetivo constatar quais tipos de Benefícios Sociais (BS) são disponibilizados aos profissionais no Brasil e a quais setores de atividade econômica eles se destinam. Na literatura, foram identificados 35 tipos de BS. Os dados foram coletados por e-mail junto a 4.560 profissionais no LinkedIn e complementados pela técnica snowball. Foram recebidas 1.781 respostas e foi realizada uma análise descritiva dos dados coletados. Constatou-se que dez BS são os mais recorrentes nas organizações estudadas (presentes em mais de 50\%) e outros sete BS estão entre os menos ofertados (presentes em menos de 15\%). Concluiu-se que a oferta de BS predomina em cinco setores de atividade econômica.

Palavras-chave: Organizações; Retenção de talentos; Benefícios sociais.

1 Possui graduação em Administração de Empresas pela Universidade Católica de Santos, UNISANTOS, mestrado em Administração pela Universidade Metodista de São Paulo, UMESP e doutorado em Comunicação Social pela Universidade Metodista de São Paulo, UMESP. Santos, São Paulo. Brasil. E-mail: albertoclaro@albertoclaro.pro.br

2 Possui graduação em Administração de Empresas pela Faculdade de Ciências Contábeis e Administrativas de Sorocaba (1984), Especialização em Gestão da Produção e materiais (FACCAS 1986), Especialização em Administração Industrial (FCAV - USP 1987), mestrado em Administração pela Pontifícia Universidade Católica de São Paulo (1995) e doutorado em Administração pela Universidade de São Paulo (2003). São Paulo. Brasil. E-mail: rogerio.profeta@ gmail.com 


\section{INTRODUÇÃO}

Entender como se dá a prática dos Benefícios Sociais (BS) nas organizações laborais é necessário, visto que a realidade da atuação profissional é cada vez mais endurecida por jornadas de trabalho duplas, triplas e sem tempo para o lazer e o bem-estar dos funcionários. Portanto, formulou-se a seguinte pergunta de pesquisa: quais BS são oferecidos pelas organizações aos seus profissionais e a que setores de atividade econômica eles se destinam? Partiu-se do pressuposto de que as organizações não possuem um programa de BS completo para atração e retenção de seu corpo profissional e esse fato pode influenciar na capacidade da organização em atrair e manter talentos.

Justifica-se este estudo em virtude de não se encontrar na revisão da literatura dados que respondam à pergunta de pesquisa, somando-se a isso o fato de que, cada vez mais, é dada importância à retenção de talentos por parte dos diversos setores da economia para atuarem em suas organizações (DUNZER; MELO; MELO, 2008) e, inclusive, pouco se verifica isso no setor acadêmico brasileiro, como demonstram Claro e Profeta (2015), e em outros setores. Assim, "a mudança no mundo empresarial atinge um elevado grau de inovação e agilidade, contemplando o ser humano como protagonista de uma nova história organizacional [...] [e de] retenção dos talentos"' (LEONARDO, 2002, p. 42).

Este estudo exploratório teve como objetivo geral verificar quais planos de BS as organizações privadas e públicas no Brasil disponibilizam para reter talentos. Como objetivos específicos, o estudo pretendeu fazer uma revisão teórica sobre plano de BS, atração e retenção de talentos, verificar a disponibilização desse plano por parte das organizações laborais junto ao corpo profissional, como forma de retê-lo ou atraí-lo para seus quadros, e verificar em que setores da atividade econômica predomina a oferta.

Como estratégia metodológica, adotou-se a pesquisa exploratória, quantitativa, com revisão teórica e aplicação de levantamento junto a profissionais que atuam em organizações laborais no Brasil. A técnica de coleta de dados partiu de: a) dados secundários: uma pesquisa bibliográfica; e b) dados primários: survey eletrônico enviado pela rede social Linkedln e estratégia de "bola de neve", também chamada de amostra por referência ou ainda snowball (indicação de novos respondentes pelos respondentes iniciais).

Os dados coletados foram analisados, num primeiro momento, a partir da busca de fatores de diferenciação, seja pela presença mais marcante de algum BS em especial (BS presentes em mais de $50 \%$ das organizações pesquisadas), seja pela ausência do BS (menos de $15 \%$ de oferta do BS pelas organizações pesquisadas). Com o uso de estatística descritiva, estratificaram-se dez BS presentes em mais de $50 \%$ das organizações e sete BS encontrados em menos de $15 \%$ das organizações.

Este trabalho é composto, além desta introdução, por revisão da literatura, aspectos metodológicos, análise dos resultados e sua apresentação, e as considerações finais.

\section{FUNDAMENTAÇÃO TEÓRICA}

Esta seção parte da discussão sobre a área de gestão de pessoas, suas políticas de BS, condições de trabalho, qualidade de vida no trabalho, atratividade de talentos profissionais, qualidade e produtividade, resultados e competitividade das organizações. A Administração, vista como ciência, tem a presunção de que a eficiência na gestão das pessoas, ou do capital intelectual, é uma fonte inesgotável de potenciais melhorias nos processos e sistemas da organização, tendo como resultado o melhor desempenho do negócio. A Escola de Relações Humanas, já na década de 1920, concluiu que o comportamento humano é influenciado pelas condições de trabalho e pela motivação dos trabalhadores e que isso influencia o desempenho. 
Sabe-se que o aspecto motivacional é composto por fatores de abrangências diversas e que os mais perenes são aqueles que se originam no próprio indivíduo. Por outro lado, existem fatores motivacionais que podem ser estimulados por meio de ações objetivas da organização, na forma de disponibilização de benefícios tangíveis e imediatos, que causem diferenciação entre as organizações enquanto opções de local de trabalho, empregadoras e retentoras de talentos. Este estudo ater-se-á à disponibilidade teórica sobre o entendimento do que Rattner (1966) já chamava de benefícios ou fringe benefits, possibilitando, assim, um recorte temático.

Sendo os trabalhadores dotados de novas características e habilidades, certamente passam a ter valor para as organizações, o que implica esforço por parte destas para contratar e manter esses profissionais. Daí resulta a estratégia de oferecer BS diferenciados, traduzidos em vantagens que as organizações ofertam para profissionais que elas necessitam para conseguir cumprir sua missão estratégica. Rosalem e Santos (2010, p. 183) afirmam que "de nada valem os benefícios da globalização econômica se não existir a globalização social", e os BS podem ser o instrumento para se criar esse tipo de organização.

Segundo Peres (2011), a concessão de BS tem sido reconhecida como diferencial estratégico pelas empresas, mas persistem desafios: como identificar quais são os benefícios que mais seriam valorizados pelos funcionários e como comunicar esses benefícios, a fim de que ajudem na retenção de talentos. A identificação das necessidades está ligada à capacidade que a empresa desenvolve de conhecer seu ambiente organizacional, por meio de ações de captação das percepções pessoais de seus empregados, e a comunicação é função da estruturação de um sistema comunicacional interno, que chegue sistematicamente a todos na empresa.

Gomes e Castro (2004, p. 32) constataram a existência de uma política de BS em uma empresa de grande porte, na qual se destacavam "os serviços de saúde (assistência médica/hospitalar), previdência social (complementação da aposentadoria), ticket refeição (ou vale alimentação), subsídios às mensalidades escolares para os empregados e seus dependentes, transporte". Pizolotto (2000) também identificou tipos de BS oferecidos pelas organizações, num ambiente que deixa de ser regulado por meras questões legais e passa a operar em condição de liberalidade, no qual elas procuram lançar mão de mais artifícios para atrair e manter seus empregados. A formalização da atividade laboral proporcionada por uma carteira de trabalho assinada também viabiliza acesso aos benefícios formais que contribuem para uma melhor qualidade de vida do trabalhador e da sua família (BRASIL, 2013), o que já não se vê quando se trata do seguro-desemprego (MOURÃO; ALMEIDA; AMARAL, 2013).

Theotônio, Reis Neto e Lopes (2013) fizeram uma análise da remuneração no Brasil segundo a legislação vigente e seus componentes: base salarial (comissões, quebra de caixa, ajuda de custo e gratificações) e remuneração variável (prêmios, participação nos lucros e resultados, participação acionária - stock options - e remuneração por habilidades e competência). Os autores perceberam que alguns tipos de remuneração não possuem legislação específica e outros possuem legislação incompleta ou defasada, causando um descompasso entre a prática das organizações privadas e a legislação.

Os BS para o grupo de organizações estudadas, segundo Pizolotto (2000), podem ser flexíveis (em que os trabalhadores escolhem aqueles que mais se adaptam ao seu perfil), os quais são destacados a seguir e servem base para a parte empírica deste estudo: creche; exame médico periódico; médico do trabalho; refeitório/restaurante; vale transporte; ajuda de custo empregado -estudante; auxílio funeral; adiantamento salarial; aluguel de casa; assistência jurídica; assistência médico-hospitalar/plano de saúde; assistência odontológica; atividades recreativas e culturais; assistência social; automóvel; auxílio-educação; auxílio-medicamentos; auxílio para cursos de idio- 
mas; bônus; cesta básica; complemento de aposentadoria/plano de seguridade social; cooperativa de crédito; cursos variados; empréstimos financeiros; estacionamento privativo; festa de Natal; reconhecimento profissional; seguro de vida em grupo; serviço profissional; serviço de prevenção de doenças profissionais; serviços facilitados; saúde e segurança do trabalho. Não se encontraram estudos teórico-empíricos que debatessem com a acuidade científica necessária esses itens ou mesmo que acrescentassem novos itens, o que é corroborado por Claro e Profeta (no prelo).

Como se pode depreender da referida lista, os tipos de BS são diversos e nem sempre de fácil mensuração quanto à influência no aspecto motivacional ou na atração/retenção dos trabalhadores e até mesmo no quanto representam de custos adicionais às organizações, já que alguns deles são imprevisíveis em seu aspecto financeiro. É certo que, à medida que os BS são incorporados na condição de salários indiretos, os salários diretos decrescem, conforme observou Arbache (1995). Em complemento aos BS, o cuidado com a Qualidade de Vida no Trabalho (QVT) passa a ser um diferencial importante. A QVT tem outra decorrência importante para as organizações: a atração/retenção de talentos, embora seja, é claro, apenas uma das variáveis que influenciam nesse fenômeno. É intuitivo considerar que ampliar a gama de BS e investir na melhoria da QVT constituem estratégias que podem levar à maior atratividade/retenção de talentos nas organizações e que ambas concorrem para melhorar o comprometimento das pessoas e, consequentemente, a produtividade delas no trabalho, muito embora tal correlação não seja tão direta, como afirmam Medeiros et al. (2003).

A operacionalização das políticas de BS, bem como das iniciativas de melhorias na QVT é de responsabilidade da área de Recursos Humanos, na maioria das organizações. Appel e Pucci (2007) apontam que as preocupações acerca da QVT não devem limitar-se apenas ao ambiente de trabalho, mas também estender-se ao entorno da organização e da vida dos empregados, pois esse contexto todo influencia os comportamentos pessoais e profissionais e, por consequência, os resultados obtidos pelos empregados em contraponto aos resultados esperados pela organização.

Dunzer, Melo e Melo (2008), por sua vez, destacam o desempenho de uma unidade de recursos humanos de uma empresa de grande porte do setor de energia no Brasil e registram que os principais fatores de atração são a oportunidade de realizar projetos desafiadores, a infraestrutura e a boa imagem da companhia, além da possibilidade de crescimento profissional. Os benefícios, a participação nos lucros e o salário adequado à função exercida também foram destacados (DUNZER; MELO; MELO, 2008).

A retenção de talentos enfrenta outros desafios, conforme aponta Leonardo (2002) quando assinala que fatores tecnológicos condicionam as necessidades de conhecimento. Há o conflito entre as expectativas individuais (satisfações pessoais, através do salário/vencimento, lazer, conforto, horário mais favorável de trabalho, oportunidades de carreira, segurança no cargo etc.) e as necessidades organizacionais (capital, edifícios, equipamentos, potencial humano, lucratividade, oportunidades de mercado etc.).

O comprometimento organizacional, que possui estudos bem difundidos (MEDEIROS et al., 2003), pesquisa sobre o vínculo do profissional com a sua carreira e envolve dois construtos - o de comprometimento e o de entrincheiramento -, cujas influências no desempenho ainda estão por ser mais bem compreendidas.

Ao analisar a relação entre benefícios e estresse no ambiente de trabalho, o estudo de Puente-Palacios, Pacheco e Severino (2013) aponta que quanto pior a percepção sobre promoções, recompensas e benefícios distribuídos, maior será o estresse. Além disso, um profissional tem objetivos, necessidades e expectativas com relação à sua atividade e ao seu ambiente de trabalho. Sendo assim, uma organização que concede um ambiente hospitaleiro para seu grupo de colaboradores também Ihes concede um benefício (CLARO, 2013). 
Outra realidade que os profissionais enfrentam é a necessidade de atualização constante, pois as organizações precisam de pessoas com competências cada vez mais diferenciadas, específicas e baseadas em tecnologia, a serem trabalhadas pelos cursos superiores (COSTA; CUNHA, 2001). Em pesquisa com egressos de um programa de pós-graduação em Administração, verificou-se que há contribuição para a formação deles, notadamente, no domínio das habilidades e dos conhecimentos técnicos e científicos, e menos sobre o domínio das capacidades relacionais, éticas, políticas e identitárias (VALADÃO JR.; RODRIGUES, 2012).

A retenção de bons profissionais é uma constante nas organizações. Gheno e Berlitz (2011) confirmam que, para reter profissionais, as organizações oferecem formas estratégicas de remuneração, além de um amplo pacote de benefícios. Segundo Gheno e Berlitz (2011, p. 10), "os benefícios sociais constituem uma importante variável no pacote de remuneração" e são "uma forma de remuneração indireta que oferece aos funcionários uma base para a satisfação de suas necessidades pessoais", podendo ser oferecidos em função do nível hierárquico dos funcionários. O plano de benefício pode ser fixo (determinado pela empresa) ou flexível (ajustado às necessidades dos funcionários). Finalizam, afirmando que "os colaboradores consideram que o plano de remuneração estratégica e o plano de benefícios incentivam o seu desempenho em busca de melhores resultados" (GHENO; BERLITZ, 2011, p. 18).

Silva (2013) verificou que determinadas organizações não têm um processo de recompensas formalizado. Finalmente, deve-se enfatizar que a concessão dos BS por parte de uma organização contribui para uma valorização dos indicadores no seu balanço social (AMARAL et al., 2013; TINOCO et al., 2011; ORO; RENNER; BRAUN; 2013).

A revisão teórica apresentada embasou o caminho definido pelos pesquisadores para esta pesquisa, caminho que é descrito na seção seguinte, dos aspectos metodológicos.

\section{MÉTODO}

Nesta seção, são abordados os procedimentos metodológicos que foram utilizados para se obter as respostas para os objetivos gerais e específicos delimitados nesta pesquisa de caráter exploratório.

\subsection{Coleta de dados}

A estratégia metodológica inicial para esta pesquisa foi a exploratória, com a elaboração de uma revisão bibliográfica; após optou-se pela estratégia quantitativa com estudo descritivo. Justifica-se a escolha deste método por explorar o assunto em um primeiro momento e permitir a continuidade do estudo em pesquisas futuras.

Com base nas dimensões detectadas na revisão teórica, redigiram-se 35 itens do instrumento de coleta de dados, que foram submetidos a pré-teste e análise semântica para verificar sua compreensão, clareza de instruções, suficiência e possíveis reações de não entendimento durante a aplicação do questionário junto aos respondentes. Os itens analisados deveriam ter a concordância ou concordância plena de cerca de $80 \%$ dos juízes para serem retidos no elenco que serviria de base para o futuro instrumento que seria criado. $\mathrm{O}$ instrumento de pesquisa continha 44 perguntas. $\mathrm{Na}$ primeira parte, referente às informações e caracterização dos respondentes, constavam nove questões que levantavam informações a respeito da amostra populacional utilizada. Na segunda parte, havia as 35 questões relativas aos BS. Os dados foram coletados por meio de levantamento eletrônico, e os dados brutos foram manualmente inseridos no banco de dados IBM SPSS Statistics 19. 
Preparou-se um formulário pelo qual se buscou caracterizar o profissional respondente quanto ao gênero, idade, estado civil, unidade e região da Federação. No âmbito profissional, os dados envolveram a identificação do tipo de organização, o setor de atividade, o tempo de trabaIho na organização, o tempo de trabalho e a função exercida na organização, esta última estratificada pelos autores em alta, média e baixa, de acordo com a posição na hierarquia da organização. O desenvolvimento da literatura possibilitou identificar 35 diferentes BS proporcionados pelas organizações aos seus profissionais empregados. Tais BS foram apresentados aleatoriamente aos sujeitos sob a condição de indicar simplesmente: existente, não existente ou não sei dizer.

A amostragem se deu por conveniência, a partir de contatos pessoais dos autores. A amostra chegou a 4.560 profissionais, que atuavam em organizações públicas ou privadas por todo o Brasil, que estavam cadastrados na rede social Linkedln e também que receberam indicação, pela técnica de "bola de neve". No período de 06 de julho a 11 de setembro de 2013, os contatos foram ativados e convidados a preencher o questionário via Google Docs. Esse período compreendeu inclusive a fase de pré-teste do questionário, respondido por 15 profissionais que estavam empregados em algum tipo de organização laboral, cujos questionários foram mantidos na tabulação, uma vez que não foi necessária nenhuma alteração do instrumento de coleta de dados, pois este atendeu às necessidades da pesquisa. Dessa forma, foram coletados 1.781 questionários completos e em condições de serem tabulados, o que representa uma taxa de resposta de $39 \%$.

Como critério de escolha dos sujeitos, foi utilizada a técnica "bola de neve". Nesse tipo de amostra, os respondentes iniciais, comuns ao meio, indicam outros respondentes com requisitos similares (HAIR JR. et al, 2005). É um método amplamente utilizado na pesquisa sociológica qualitativa, pelo fato de referenciar pessoas com alguma característica semelhante que são de interesse da pesquisa (BIERNACKI; WALDORF, 1981). Como requisito fundamental desta pesquisa, todos os respondentes deveriam ser usuários da rede social Linkedln.

\subsection{Análise dos dados}

Após a coleta dos dados, foi gerado um arquivo no software MS Excel 2010, tendo seus campos conferidos e corrigidos (editados) para se encontrar erros de digitação, respostas ilegíveis, inconsistências, ambiguidades ou inconformidades. No total, foram 1.781 registros de respostas adequados para se iniciar a análise dos dados. A partir daí, começou-se a utilizar o software IBM SPSS Statistics 19.0 para analisar os dados. Assim que a planilha foi aberta no programa, procedeu-se à correção de nomenclatura das labels. Após se iniciou a análise de dados com o uso da técnica da estatística descritiva baseada em frequências.

As tabelas de frequência indicaram cada valor distinto de uma variável categórica, juntamente com uma contagem do número de vezes em que esse valor ocorreu e as percentagens relativas às contagens (usou-se o comando Output do SPSS). No programa, as frequências são obtidas escolhendo, no menu, Statistics $>$ Summarize $>$ Frequencies.

\subsection{Caracterização dos respondentes}

Com a finalidade de facilitar a tabulação, as profissões com flexão de gênero foram ajustadas ao termo masculino. Predominam homens (57\%) em relação às mulheres (43\%), e a média da faixa etária dos homens (35,5 anos) é maior que a das mulheres (32,3 anos). Quanto ao estado civil, $47.6 \%$ são casados, $38 \%$ solteiros, $6 \%$ separados/divorciados, $8 \%$ mantêm união estável e $0,4 \%$ são viúvos. Quanto à formação, predominam os graduados (bacharelado, licenciatura ou 
tecnólogo) com 53,5\%, seguidos pelos pós-graduados lato sensu (especialização, MBA - Master Business Administration), com 27\%; os com Ensino Médio ou Técnico, com 9\%, os com mestrado, $8 \%$, e os com doutorado, 2\%. As demais escolaridades (Ensino Fundamental, pós-doutorado e livre docência) representam $0,5 \%$ dos respondentes.

Quanto à posição na hierarquia, nas organizações representadas, os empregados considerados na posição alta representam $4 \%$; a posição média $28 \%$ e a posição baixa $67 \%$. Em $1 \%$ dos respondentes não foi possível precisar a posição hierárquica.

\subsection{Caracterização das organizações representadas}

Os principais setores de atividade econômica, com base na Classificação Nacional de Atividades Econômicas do Cadastro Nacional de Atividades Econômicas (CNAE) (IBGE, 2013), estão detalhados na Tabela 1.

Tabela 1 - Setores de atividade econômica representados na pesquisa

\begin{tabular}{lcc}
\hline Setor de atividade econômica & Frequência & $\%$ \\
\hline Administração pública, defesa e seguridade social & 85 & $5 \%$ \\
Agricultura, pecuária, silvicultura e exploração florestal & 35 & $2 \%$ \\
Alojamento e alimentação & 36 & $2 \%$ \\
Atividades imobiliárias, aluguéis e serviços prestados às empresas & $2 \%$ \\
Automação, instrumentação e projetos & 37 \\
Comércio; Reparação de veículos automotores, objetos pessoais e domésticos & 11 \\
Comunicação & 123 \\
Construção & 18 & $7 \%$ \\
Cultura, lazer e turismo & $53 \%$ \\
Educação & $3 \%$ \\
Indústrias de transformação & 2 \\
Indústrias extrativas & 277 & $16 \%$ \\
Intermediação financeira, seguros, previdência complementar e serviços relacio- & 504 & $28 \%$ \\
nados & 11 & $1 \%$ \\
Não identificado & 67 & $4 \%$ \\
Organismos internacionais e outras instituições extraterritoriais & 167 & $9 \%$ \\
Outros serviços coletivos, sociais e pessoais & 12 & $1 \%$ \\
Produção e distribuição de eletricidade, gás e água & 112 & $6 \%$ \\
Saúde e serviços sociais & 26 & $1 \%$ \\
Tecnologia da informação & 121 & $7 \%$ \\
Transporte, armazenagem e comunicações & 26 & $1 \%$ \\
\hline Total geral & 58 & $3 \%$ \\
\hline Fonte: elaborada pelos autores. & 1.781 & $100 \%$ \\
\hline
\end{tabular}

A maioria dos respondentes (63\%) está na organização entre zero e cinco anos, seguidos por $20 \%$ que estão na organização há mais de dez anos. Os 17\% restantes estão na organização entre seis e dez anos. Em termos de experiência profissional, predominam empregados com mais de dez anos de experiência (47\%), seguidos por $29 \%$ com menos de cinco anos de experiência, e os restantes, $24 \%$, possuem entre seis e dez anos de experiência.

Quanto ao tipo de organização, predominam empresas privadas (78\%), pública municipal (8\%), pública estadual (6\%), pública federal (3\%) e empresas de capital misto (1\%). Quatro por cento não responderam ou preferiram não informar. Em relação à região das organizações dos pesquisados, a região Sudeste (87\%) predominou entre os respondentes, seguida pelas regiões Sul (5\%), Centro Oeste (5\%), Norte (2\%) e Nordeste (1\%). 


\section{APRESENTAÇÃO DOS RESULTADOS DA PESQUISA}

\subsection{Resultados preliminares}

Os resultados apresentados a seguir, baseados no método explicado na seção anterior, são considerados preliminares na medida em que se buscou caracterizá-los apenas pelo uso do método descritivo, como forma de identificar, neste primeiro momento, as principais características. A partir da verificação das respostas existentes, para cada BS pesquisado, foram identificados dez BS mostrados como presentes em mais de $50 \%$ das organizações representadas na pesquisa. A Tabela 2 apresenta esses dados.

Tabela 2 - Top 10

\begin{tabular}{ccccccccccc}
\hline Top 10 & VT & CM & EO & E & EMP & AS & CN & RR & MT & CF \\
\hline Existente & 1.405 & 1.352 & 1.190 & 1.173 & 1.183 & 1.105 & 1.108 & 1.087 & 947 & 909 \\
Não existente & 306 & 401 & 377 & 570 & 519 & 566 & 578 & 659 & 728 & 786 \\
Não sei dizer & 70 & 28 & 214 & 38 & 79 & 110 & 95 & 35 & 106 & 86 \\
\hline Total & 1.781 & 1.781 & 1.781 & 1.781 & 1.781 & 1.781 & 1.781 & 1.781 & 1.781 & 1.781 \\
\hline Existente & $79 \%$ & $76 \%$ & $67 \%$ & $66 \%$ & $66 \%$ & $62 \%$ & $62 \%$ & $61 \%$ & $53 \%$ & $51 \%$ \\
Não existente & $17 \%$ & $23 \%$ & $21 \%$ & $32 \%$ & $29 \%$ & $32 \%$ & $32 \%$ & $37 \%$ & $41 \%$ & $44 \%$ \\
Não sei dizer & $4 \%$ & $2 \%$ & $12 \%$ & $2 \%$ & $4 \%$ & $6 \%$ & $5 \%$ & $2 \%$ & $6 \%$ & $5 \%$ \\
\hline
\end{tabular}

*VT = Vale Transporte. $\mathrm{CM}=$ Convênio Médico. EO = E-mail da Organização. E = Estacionamento. EMP = Exame Médico Periódico. AS = Adiantamento Salarial. $\mathrm{CN}=$ Confraternização de Natal. $\mathrm{RR}=$ Refeitório/Restaurante. $\mathrm{MT}=$ Médico do Trabalho. $\mathrm{CF}=$ Convênio com Farmácias.

Fonte: elaborada pelos autores.

A partir da constatação de quais são os principais BS ofertados pelas organizações, foram identificados os principais resultados, relacionados ao tipo da organização, à região da Federação onde ela está instalada, à posição do respondente na hierarquia da organização e ao nível de escolaridade, com o objetivo de entender as diferenças, ainda que a partir de uma análise quantitativa. Será dado destaque às variáveis que superarem a média.

Vale transporte $=$ média $79 \%$. Este também é um BS que, às vezes, é obrigatório pela Convenção Coletiva do Trabalhador e presta-se a minimizar os custos de transporte dos profissionais. As empresas públicas federais $(92 \%)$ e privadas (83\%) destacam-se na oferta deste BS. As regiões Centro Oeste (84\%), Norte $(83 \%)$ e Sul $(82 \%)$ concentram as maiores ofertas do BS. É um BS mais presente nas posições média (82\%) e baixa (78\%), entre os pesquisados. O BS foi constatado como mais frequente entre os que têm pós-graduação lato sensu (81\%), os que têm graduação (80\%) e os que têm Ensino Médio (79\%).

Convênio médico $=$ média $76 \%$. A saúde da equipe de profissionais pode vir a constituir um diferencial numa organização minimamente "visionária". Mais saúde implica menor absenteísmo por afastamento médico, por exemplo, o que pode significar mais produtividade operacional. Em caso específico, menor índice de absenteísmo implica menos problemas na gestão operacional e maior expectativa de reflexos positivos no aproveitamento, na medida em que os profissionais estão mais disponíveis para o trabalho (MARQUES; MARTINS; CRUZ SOBRINHO, 2011). Este BS foi encontrado predominantemente em empresa pública federal (82\%) e em empresa privada (79\%). As regiões Norte $(93 \%)$, Nordeste $(87 \%)$ e Sudeste $(77 \%)$ são as que oferecem o BS acima da média. Os profissionais em posição hierárquica média (88\%) são os mais beneficiados pelo convênio médico. Quanto à escolaridade, todas as titulações acima da graduação mostraram ter maior acesso ao BS: livre docência e pós-doutorado (ambos com 100\%), pósgraduação lato sensu (84\%), doutorado (81\%) e mestrado (80\%). 
E-mail da organização = média $67 \%$. O e-mail é uma forma importante de comunicação entre pessoas e organizações. A disponibilização desta tecnologia aos profissionais, além de ser um diferencial, passa a ser uma estratégia, na medida em que cria um canal específico de comunicação. As empresas de capital misto se destacam na oferta deste BS (100\%), seguidas pelas empresas públicas federais, que disponibilizam este BS na escala de 94\%. Foi nas regiões Sul (68\%) e Sudeste (67\%) que foram constatadas as mais expressivas presenças deste BS. A posição hierárquica alta conta com este BS em $75 \%$ das organizações, seguida pela posição hierárquica média, com $73 \%$ das respostas. Novamente a maior escolaridade possibilita maior acesso a este BS: livre-docência e pósdoutorado (100\%), doutorado (95\%), mestrado (82\%) e pós-graduação lato sensu (75\%).

Oferta de estacionamento próprio $=$ média $66 \%$. O acesso ao automóvel próprio passou a ser mais presente e, com isso, a necessidade de se ter onde estacionar os veículos chega a ser uma preocupação importante. A organização que oferece tal BS está, de fato, resolvendo um problema para o profissional, além de reduzir os custos de transporte (considerando que tal estacionamento seja subsidiado pela organização). Destaque para as empresas privadas, das quais $68 \%$ ofertam este BS. Na região Nordeste, $87 \%$ das organizações disponibilizam estacionamento para seus profissionais, enquanto na região Sudeste este índice chega a $67 \%$ das organizações. A posição hierárquica média desfruta do BS em $72 \%$ das organizações. Novamente a maior escolaridade possibilita maior acesso a este BS: livre-docência e pós-doutorado (100\%), doutorado (84\%), mestrado (75\%) e pós-graduação lato sensu (70\%).

Exame médico periódico = média $66 \%$. Na mesma linha do BS convênio médico, disponibilizar a facilidade de realizar exames médicos periódicos pode caracterizar-se como um potencial diferencial, na medida em que possibilita fragrante melhoria na qualidade de vida. As empresas de capital misto, com $100 \%$, e as empresas privadas, com $73 \%$, são as que mais ofertam este BS. A região Nordeste, com $80 \%$, seguida pelas regiões Norte (76\%) e Sudeste (67\%) superam as demais regiões na oferta de exame médico periódico. Ao contrário do que se poderia esperar, é a posição hierárquica média a que mais conta com este BS (79\%). Constatou-se outra vez que a maior escolaridade possibilita maior acesso a este BS: livre-docência e pós-doutorado (100\%), doutorado (84\%), mestrado (72\%) e pós-graduação lato sensu (73\%).

Adiantamento salarial = média $6 \mathbf{2 \%}$. Apesar de representar um custo, a antecipação do salário/vencimento por parte da organização pode representar um diferencial, na medida em que possibilita ao profissional antecipar-se em suas necessidades financeiras. Apenas as empresas privadas, em $72 \%$ dos casos, oferecem este BS, o qual está mais presente nas regiões Norte (72\%) e Sudeste (62\%). Novamente a posição hierárquica média (67\%) é a que mais se beneficia deste BS. Os profissionais com graduação (67\%) e com pós-graduação lato sensu (65\%) estão entre os que mais percebem este BS.

Confraternização de Natal = média $62 \%$. A integração entre os profissionais e seus familiares, possibilitada, ainda que superficialmente, pela confraternização de Natal, estreita os laços entre eles, quando extensiva à família, além de ampliar os laços de todos com a organização. As empresas de capital misto, com $89 \%$, e as empresas privadas, com $66 \%$, são as que mais ofertam este BS. As das regiões Nordeste (73\%), Norte (69\%), Sudeste (62\%) e Centro Oeste (62\%), quase que uniformemente, oferecem este BS. A posição hierárquica alta conta com este BS em $68 \%$ das organizações, seguida pela posição hierárquica média, com $66 \%$ das respostas. Mais uma vez a melhor formação possibilita mais acesso ao BS: livre-docência (100\%) e pós-doutorado (75\%). Exceção deve ser feita aos graduados, com $65 \%$ de acesso ao BS.

Refeitório/Restaurante $=$ média $61 \%$. A comodidade e a melhoria potencial na qualidade de vida dos profissionais geralmente são os principais atrativos para a implantação de um restaurante/refeitório na organização, dado que melhora a possibilidade de os profissionais terem acesso a 
refeições mais adequadas, além de possibilitar redução do custo da alimentação, seja pela qualidade dos alimentos servidos no local de trabalho, seja pela comodidade de acesso às refeições sem necessidade de deslocamento. Apenas as empresas privadas, em $67 \%$ dos casos, oferecem este BS. As organizações das regiões Nordeste (73\%), Norte (69\%) e Sudeste (61\%) oferecem este BS. Novamente a posição hierárquica média (67\%) é a que mais se beneficia deste benefício. Constatou-se que a maior escolaridade possibilita maior acesso a este BS: livre-docentes (100\%), pós-doutores (75\%), pós-graduados lato sensu (65\%) e graduados (62\%) estão entre os que mais percebem este BS.

Médico do trabalho = média 53\%. A disponibilidade de profissional da saúde no ambiente de trabalho complementa os BS de convênio médico e exame médico periódico e também contribui para a melhoria potencial da qualidade de vida. Empresas de capital misto (67\%), pública federal (63\%), pública municipal (61\%), seguidas pelas empresas privadas (54\%), destacam-se na oferta deste BS. As organizações das regiões Nordeste (73\%), Norte (62\%) e Sudeste (54\%) oferecem este BS. Novamente a posição hierárquica média (62\%) é a que mais se beneficia deste BS. Constatou-se que a maior escolaridade possibilita maior acesso a este BS: livre-docência (100\%), pós-doutorado (75\%), pós-graduação lato sensu (60\%) e mestrado (55\%) estão entre os que mais percebem este BS.

Convênio com farmácias = média $\mathbf{5 1 \%}$. Da mesma forma que o convênio médico e o exame médico periódico, o convênio com farmácias também contribui para a melhoria potencial da qualidade de vida. As empresas privadas, com $57 \%$, estão entre as que mais ofertam este BS. Foi nas regiões Nordeste (53\%), Norte e Sudeste ( $52 \%$ cada) que se constatou a maior oferta do BS do convênio com farmácias. Novamente a posição hierárquica média (59\%) é a que mais se beneficia deste BS. Os profissionais com escolaridade de mestrado (53\%) e pós-doutorado (100\%) estão entre os que mais percebem este tipo de BS.

A Tabela 3 sintetiza os limites superiores em termos de porcentagem de ocorrência dos principais BS face às variáveis estudadas. Nota-se que, em relação ao tipo de organização, as empresas de capital misto e as empresas privadas são as que mais se destacam na liderança de oferta de BS, com quatro ocorrências para cada uma, seguidas pela empresa pública federal, com duas ocorrências. Já quanto à região, o Nordeste, com seis ocorrências, é a região que apresenta maior oferta do BS, seguido pela região Norte, com duas ocorrências, e pelas regiões Centro Oeste e Sul, com uma ocorrência cada. A região Sudeste não aparece em destaque em nenhum dos BS top 10. Quanto à posição hierárquica, amplo destaque deve ser dado à posição média, com oito ocorrências, contra duas ocorrências da posição alta. Com relação à escolaridade, as escolaridades mais elevadas têm amplo destaque, com apenas um BS levando ao destaque a escolaridade graduação. 
Tabela 3 - Destaques top 10

\begin{tabular}{|c|c|c|c|c|c|c|c|c|c|c|}
\hline $\begin{array}{c}\text { Top } \\
10\end{array}$ & VT & CM & $E O$ & E & EMP & AS & $\mathrm{CN}$ & RR & MT & CF \\
\hline BS & $79 \%$ & $76 \%$ & $67 \%$ & $66 \%$ & $66 \%$ & $62 \%$ & $62 \%$ & $61 \%$ & $53 \%$ & $51 \%$ \\
\hline TO & $\begin{array}{c}\text { Pública } \\
\text { federal } \\
(92 \%)\end{array}$ & $\begin{array}{c}\text { Pública } \\
\text { federal } \\
(82 \%)\end{array}$ & $\begin{array}{l}\text { Empre- } \\
\text { sa de } \\
\text { capital } \\
\text { misto } \\
(100 \%)\end{array}$ & $\begin{array}{c}\text { Empresa } \\
\text { privada } \\
(68 \%)\end{array}$ & $\begin{array}{l}\text { Empre- } \\
\text { sa de } \\
\text { capital } \\
\text { misto } \\
(100 \%)\end{array}$ & $\begin{array}{c}\text { Empresa } \\
\text { privada } \\
(72 \%)\end{array}$ & $\begin{array}{c}\text { Empre- } \\
\text { sa de } \\
\text { capital } \\
\text { misto } \\
(89 \%)\end{array}$ & $\begin{array}{c}\text { Em- } \\
\text { presa } \\
\text { privada } \\
(67 \%)\end{array}$ & $\begin{array}{c}\text { Empre- } \\
\text { sa de } \\
\text { capital } \\
\text { misto } \\
(67 \%)\end{array}$ & $\begin{array}{c}\text { Empresa } \\
\text { privada } \\
(57 \%)\end{array}$ \\
\hline $\mathbf{R}$ & $\begin{array}{c}\text { Centro } \\
\text { Oeste } \\
(84 \%)\end{array}$ & $\begin{array}{l}\text { Norte } \\
(93 \%)\end{array}$ & $\begin{array}{l}\text { Sul } \\
(68 \%)\end{array}$ & $\begin{array}{l}\text { Nordes- } \\
\text { te }(87 \%)\end{array}$ & $\begin{array}{l}\text { Nordes- } \\
\text { te }(80 \%)\end{array}$ & $\begin{array}{l}\text { Norte } \\
(72 \%)\end{array}$ & $\begin{array}{l}\text { Nordes- } \\
\text { te (73\%) }\end{array}$ & $\begin{array}{l}\text { Nordes- } \\
\text { te }(73 \%)\end{array}$ & $\begin{array}{l}\text { Nordes- } \\
\text { te (73\%) }\end{array}$ & $\begin{array}{l}\text { Nordes- } \\
\text { te }(53 \%)\end{array}$ \\
\hline H & $\begin{array}{l}\text { Média } \\
(82 \%)\end{array}$ & $\begin{array}{l}\text { Média } \\
(88 \%)\end{array}$ & $\begin{array}{c}\text { Alta } \\
(75 \%)\end{array}$ & $\begin{array}{l}\text { Média } \\
(72 \%)\end{array}$ & $\begin{array}{l}\text { Média } \\
(79 \%)\end{array}$ & $\begin{array}{l}\text { Média } \\
(67 \%)\end{array}$ & $\begin{array}{c}\text { Alta } \\
(68 \%)\end{array}$ & $\begin{array}{l}\text { Média } \\
(67 \%)\end{array}$ & $\begin{array}{l}\text { Média } \\
(62 \%)\end{array}$ & $\begin{array}{l}\text { Média } \\
(59 \%)\end{array}$ \\
\hline Esc. & $\begin{array}{c}\text { PG } \\
\text { lato } \\
\text { sensu } \\
(81 \%)\end{array}$ & $\begin{array}{c}\text { Livre- } \\
\text { do- } \\
\text { cência } \\
\text { Pós-doc } \\
(100 \%)\end{array}$ & $\begin{array}{l}\text { Livre- } \\
\text { docên- } \\
\text { cia } \\
\text { Pós-doc } \\
(100 \%)\end{array}$ & $\begin{array}{l}\text { Livre- } \\
\text { do- } \\
\text { cência } \\
\text { Pós-doc } \\
(100 \%)\end{array}$ & $\begin{array}{c}\text { Livre- } \\
\text { do- } \\
\text { cência } \\
\text { Pós-doc } \\
(100 \%)\end{array}$ & $\begin{array}{l}\text { Gradua- } \\
\text { ção (67\%) }\end{array}$ & $\begin{array}{l}\text { Livre- } \\
\text { do- } \\
\text { cência } \\
(100 \%)\end{array}$ & $\begin{array}{l}\text { Livre- } \\
\text { do- } \\
\text { cência } \\
(100 \%)\end{array}$ & $\begin{array}{l}\text { Livre- } \\
\text { do- } \\
\text { cência } \\
(100 \%)\end{array}$ & $\begin{array}{l}\text { Pós-doc } \\
(100 \%),\end{array}$ \\
\hline
\end{tabular}

*VT = Vale Transporte. CM = Convênio Médico. EO = E-mail da Organização. E = Estacionamento. EMP = Exame Médico Periódico. $\mathrm{AS}=$ Adiantamento Salarial. $\mathrm{CN}=$ Confraternização de Natal. $\mathrm{RR}=$ Refeitório/Restaurante. $\mathrm{MT}=\mathrm{Médico}$ do Trabalho. $\mathrm{CF}=$ Convênio com Farmácias. $\mathrm{BS}=$ Benefício Social. ESC = Escolaridade. $\mathrm{TO}=$ Tipo de Organização. $\mathrm{H}=$ Hierarquia. $\mathrm{R}=$ Região. $\mathrm{PG}=$ Pós-Graduação. Pós-Doc = Pós-Doutorado.

Fonte: elaborada pelos autores.

Merecem destaque também aqueles BS que estão menos presentes nas organizações pesquisadas, pelo fato de poderem ser, potencialmente, fatores de diferenciação entre os BS disponíveis para os profissionais dos diversos setores da economia do Brasil. Para ilustrá-los, destacam-se aqueles que foram referenciados em menos de $15 \%$ das respostas. A Tabela 4 ilustra tais benefícios.

Tabela 4-Down 7

\begin{tabular}{|c|c|c|c|c|c|c|c|}
\hline Down 7 & Creche & $\begin{array}{c}\text { Automó- } \\
\text { vel }\end{array}$ & $\begin{array}{l}\text { Atendimento } \\
\text { psicológico }\end{array}$ & $\begin{array}{c}\text { Cooperativa } \\
\text { de crédito }\end{array}$ & $\begin{array}{c}\text { Auxílio medi- } \\
\text { camentos }\end{array}$ & $\begin{array}{c}\text { Assistência } \\
\text { jurídica }\end{array}$ & $\begin{array}{l}\text { Aluguel } \\
\text { de casa }\end{array}$ \\
\hline Existente & 391 & 342 & 324 & 308 & 249 & 232 & 91 \\
\hline $\begin{array}{l}\text { Não exis- } \\
\text { tente }\end{array}$ & 1.126 & 1301 & 1.264 & 1.259 & 1.359 & 1.263 & 1.481 \\
\hline $\begin{array}{l}\text { Não sei } \\
\text { dizer }\end{array}$ & 264 & 138 & 193 & 214 & 173 & 286 & 209 \\
\hline Total & 1.781 & 1.781 & 1781 & 1.781 & 1.781 & 1.781 & 1.781 \\
\hline Existente & $22 \%$ & $19 \%$ & $18 \%$ & $17 \%$ & $14 \%$ & $13 \%$ & $5 \%$ \\
\hline $\begin{array}{l}\text { Não exis- } \\
\text { tente }\end{array}$ & $63 \%$ & $73 \%$ & $71 \%$ & $71 \%$ & $76 \%$ & $71 \%$ & $83 \%$ \\
\hline $\begin{array}{l}\text { Não sei } \\
\text { dizer }\end{array}$ & $15 \%$ & $8 \%$ & $11 \%$ & $12 \%$ & $10 \%$ & $16 \%$ & $12 \%$ \\
\hline
\end{tabular}

Fonte: elaborada pelos autores.

A partir da constatação de quais são os principais BS ofertados pelas organizações, foram identificados os resultados relacionados ao tipo da organização, à região da Federação onde ela está instalada, à posição do respondente na hierarquia da organização, ao setor de atividade e ao nível de escolaridade, com o objetivo de entender, ainda que superficialmente, as diferenças entre eles. 
Disponibilização de serviços de creche = média $22 \%$. Este tipo de BS pode caracterizarse num importante diferencial para os profissionais que estiverem na fase inicial da constituição da família, sem precisar contar com a estrutura do poder público, nem sempre presente. As empresas públicas, nos níveis federal (45\%), estadual (34\%) e municipal (26\%), mais as empresas de capital misto (44\%) superam a média na oferta deste BS. Na região Nordeste (33\%) é que se encontram as maiores ofertas deste BS, seguida pela região Sudeste, ainda que com apenas $22 \%$ de oferta. Novamente a posição hierárquica média (27\%) é a que mais se beneficia deste BS. Profissionais com escolaridade de livre-docência e pós-doutorado, ambos no nível de 50\%, estão entre os que mais têm acesso a este BS, seguidos pelos pós-graduados em lato sensu (26\%).

Automóvel $=$ média $19 \%$. Disponibilizar acesso a automóvel subsidiado é uma estratégia de diferenciação em BS empregada pelas organizações em geral, embora seja pouco comum, conforme foi constatado por esta pesquisa. Apenas as empresas privadas (20\%) superam a média da oferta deste BS. No que tange à região da Federação, cabe destaque à região Sudeste (20\%) na oferta deste BS. Somente os profissionais em posição hierárquica alta (13\%) encontram a oferta deste BS acima da média das demais posições. Os profissionais com escolaridade de livre-docente $(50 \%)$ estão entre os que mais têm acesso a este BS.

Atendimento psicológico = média $\mathbf{1 8 \%}$. Na mesma linha do BS convênio médico, disponibilizar aos profissionais a facilidade de realizar atendimento psicológico pode caracterizar-se como um potencial diferencial, na medida em que possibilita fragrante melhoria na qualidade de vida. As empresas públicas federais (47\%) e de capital misto (33\%) destacam-se na oferta deste BS. As regiões Nordeste (20\%) e Sudeste (19\%) superam sutilmente as demais na oferta de atendimento psicológico aos profissionais. Destaque deve ser dado para a posição hierárquica média (23\%), quanto ao acesso a este BS. De maneira geral, a maior escolaridade está associada à maior percepção deste tipo de BS: livre-docente (50\%), pós-doutor (50\%), doutor (30\%), mestre (27\%) e pós-graduado lato sensu (23\%).

Cooperativa de crédito = média $\mathbf{1 7 \%}$. Visando apoiar os profissionais nas situações em que um aporte adicional de recursos financeiros seja necessário, a constituição de uma cooperativa de crédito, embora não implique grande investimento, também é um BS raro nas organizações. As empresas de capital misto (56\%), seguidas pelas empresas públicas federais (24\%), estaduais $(19 \%)$ e privadas (18\%), estão entre as que superam a média de oferta deste BS. As regiões Nordeste (33\%), Norte (21\%) e Sudeste (18\%) destacam-se pela oferta de cooperativa de crédito acima da média das outras regiões. Os profissionais em posição hierárquica média (21\%) percebem mais este tipo de BS que os de outras posições hierárquicas. Profissionais com escolaridade de livre-docência (50\%) e os com pós-graduação lato sensu (21\%) estão entre os que se destacam no recebimento deste BS.

Auxílio medicamentos = média 14\%. Na mesma linha de outros três BS análogos (convênio médico, exames médicos periódicos e médico do trabalho), o auxílio medicamentos visa aumentar a qualidade de vida dos profissionais, além de minimizar os custos da aquisição de medicamentos. As empresas de capital misto (44\%), públicas federais $(18 \%)$ e privadas $(15 \%)$ destacam-se na oferta de auxílio medicamentos. Nas regiões Nordeste (27\%) e Norte $(24 \%)$ mais se observou a oferta deste BS. Apenas a posição hierárquica média (16\%) supera a média da oferta deste BS. Profissionais com escolaridade de livre-docente $(50 \%)$ e os com pós-graduação lato sensu (16\%) estão entre os que se destacam no recebimento deste BS.

Assistência jurídica $=$ média $13 \%$. Disponibilizar algum tipo de BS nesse sentido destina-se a minimizar as dificuldades do profissional em ocasiões em que precise de alguma orientação jurídica acessível e sem custo (ou com custo subsidiado). Apenas as empresas de capital 
misto, com $22 \%$ de ocorrência, superam a média da oferta deste tipo de BS. Entre as regiões, destacam-se a região Norte (17\%) e Sudeste (14\%) em termos de oferta de assistência jurídica aos profissionais. A disponibilização desse BS é maior que a média para profissionais de posição hierárquica média (16\%). A escolaridade maior possibilita mais acesso a este BS: livre-docência (50\%), doutorado (27\%), pós-doutorado (25\%) e mestrado (14\%).

Aluguel de casa $=$ média $\mathbf{5 \%}$. Este é outro BS que tem impacto na redução dos custos dos profissionais, na medida em que evita que parte do salário/vencimento seja destinada a pagamento de aluguel residencial. Empresas públicas federais (10\%) e empresas privadas (6\%) oferecem o BS de pagamento de aluguel de casa de seus profissionais. Nas regiões Norte (14\%) e Nordeste (7\%), a oferta deste BS foi mais presente. Apenas profissionais em posição hierárquica alta (13\%) têm acesso a este BS acima da média dos outros profissionais. Os profissionais com escolaridade de livre-docente (50\%) estão entre os que mais se destacam da percepção deste BS.

A Tabela 5 mostra os principais destaques entre os BS estudados, frente às variáveis consideradas. Em relação ao tipo de organização, as empresas pública federal e de capital misto, com três destaques cada, sobressaíram-se frente às demais. A empresa privada aparece como destaque em apenas um dos BS down 7. Quanto à região, sobressaem-se as regiões Norte e Nordeste, com três destaques cada, e a região Sudeste, com um destaque entre os BS down 7. Já para a posição hierárquica, novamente a posição média, com cinco destaques, supera a posição alta, que apareceu em apenas dois destaques. Na variável escolaridade, verifica-se total predomínio de destaques para as escolaridades mais elevadas.

Tabela 5 - Destaques down 7

\begin{tabular}{|c|c|c|c|c|c|c|c|}
\hline Down 7 & Creche & $\begin{array}{l}\text { Automó- } \\
\text { vel }\end{array}$ & $\begin{array}{l}\text { Atendimen- } \\
\text { to psicoló- } \\
\text { gico }\end{array}$ & $\begin{array}{l}\text { Cooperativa } \\
\text { de crédito }\end{array}$ & $\begin{array}{l}\text { Auxílio medi- } \\
\text { camentos }\end{array}$ & $\begin{array}{l}\text { Assistência } \\
\text { jurídica }\end{array}$ & $\begin{array}{l}\text { Aluguel } \\
\text { de casa }\end{array}$ \\
\hline $\begin{array}{c}\text { Média por } \\
\text { BS }\end{array}$ & $22 \%$ & $19 \%$ & $18 \%$ & $17 \%$ & $14 \%$ & $13 \%$ & $5 \%$ \\
\hline $\begin{array}{l}\text { Tipo de or- } \\
\text { ganização }\end{array}$ & $\begin{array}{l}\text { Pública } \\
\text { federal } \\
(45 \%)\end{array}$ & $\begin{array}{c}\text { Empresas } \\
\text { privadas } \\
(20 \%)\end{array}$ & $\begin{array}{l}\text { Pública fede- } \\
\text { ral }(47 \%)\end{array}$ & $\begin{array}{c}\text { Empresas } \\
\text { de capital } \\
\text { misto }(56 \%)\end{array}$ & $\begin{array}{c}\text { Empresas de } \\
\text { capital misto } \\
(44 \%)\end{array}$ & $\begin{array}{c}\text { Empresas } \\
\text { de capi- } \\
\text { tal misto } \\
(22 \%)\end{array}$ & $\begin{array}{c}\text { Pública } \\
\text { federal } \\
(10 \%)\end{array}$ \\
\hline Região & $\begin{array}{c}\text { Nordeste } \\
(33 \%)\end{array}$ & $\begin{array}{l}\text { Sudeste } \\
(20 \%)\end{array}$ & $\begin{array}{c}\text { Nordeste } \\
(20 \%)\end{array}$ & $\begin{array}{c}\text { Nordeste } \\
(33 \%)\end{array}$ & $\begin{array}{c}\text { Nordeste } \\
(27 \%)\end{array}$ & $\begin{array}{l}\text { Norte } \\
(17 \%)\end{array}$ & $\begin{array}{l}\text { Norte } \\
(14 \%)\end{array}$ \\
\hline Posição & $\begin{array}{l}\text { Média } \\
(27 \%)\end{array}$ & Alta (13\%) & Média (23\%) & $\begin{array}{l}\text { Média } \\
(21 \%)\end{array}$ & Média (16\%) & $\begin{array}{l}\text { Média } \\
(16 \%)\end{array}$ & $\begin{array}{c}\text { Alta } \\
(13 \%)\end{array}$ \\
\hline Escolaridade & $\begin{array}{l}\text { Livre-do- } \\
\text { cência e } \\
\text { Pós-dou- } \\
\text { torado } \\
(50 \%)\end{array}$ & $\begin{array}{l}\text { Livre-do- } \\
\text { cência } \\
(50 \%)\end{array}$ & $\begin{array}{l}\text { Livre-docên- } \\
\text { cia e Pós- } \\
\text { doutorado } \\
(50 \%)\end{array}$ & $\begin{array}{l}\text { Livre-docên- } \\
\text { cia }(50 \%)\end{array}$ & $\begin{array}{l}\text { Livre-docência } \\
(50 \%)\end{array}$ & $\begin{array}{l}\text { Livre-do- } \\
\text { cência } \\
(50 \%)\end{array}$ & $\begin{array}{l}\text { Livre- } \\
\text { do- } \\
\text { cência } \\
(50 \%)\end{array}$ \\
\hline
\end{tabular}

Fonte: elaborada pelos autores.

Uma breve análise da oferta de BS por setor de atividade mostra algumas "ilhas de prosperidade", como pode ser visto na Tabela 6. 
Tabela 6 - Destaques por setor de atividade econômica

\begin{tabular}{|c|c|c|c|c|c|c|c|c|c|c|c|c|c|c|c|c|c|}
\hline Setor & VT & CM & EO & E & EM & AS & $\mathrm{CN}$ & RR & MT & CF & C & A & AP & CC & AM & AJ & AC \\
\hline Média BS & 79 & 76 & 67 & 66 & 66 & 62 & 62 & 61 & 53 & 51 & 22 & 19 & 18 & 17 & 14 & 13 & 5 \\
\hline $\begin{array}{c}\text { Indústrias Extra- } \\
\text { tivas } \\
\end{array}$ & 100 & 82 & 73 & 73 & 91 & 73 & 73 & 82 & 91 & 82 & & & 27 & 55 & 64 & 36 & 9 \\
\hline $\begin{array}{l}\text { Indústrias de } \\
\text { Transform. }\end{array}$ & 87 & 90 & 71 & 87 & 89 & 90 & 67 & 91 & 75 & 75 & & 25 & 19 & 30 & 19 & & 6 \\
\hline $\begin{array}{l}\text { Agricult, Pecuária, } \\
\text { Silvic. e Explora- } \\
\text { ção Florestal }\end{array}$ & & 80 & 69 & 80 & 69 & 69 & 74 & & 69 & 66 & 43 & 43 & 23 & 29 & 43 & 23 & 11 \\
\hline $\begin{array}{c}\text { Transp., Armaz. } \\
\text { Comunic. }\end{array}$ & 88 & 78 & & 76 & 69 & 66 & & 69 & 57 & 52 & & 24 & 26 & & 21 & 19 & 12 \\
\hline Aloj. e Aliment. & 97 & 81 & & 72 & 78 & 72 & 67 & 81 & 58 & 58 & 25 & & & & & 17 & 8 \\
\hline $\begin{array}{l}\text { Intermed. Financ., } \\
\text { Seguros, } \\
\text { Previd. Complem. } \\
\text { e Serviços Rela- } \\
\text { cion. }\end{array}$ & 88 & 91 & 79 & & 84 & & 82 & & 54 & & 52 & & 31 & 33 & & 22 & 6 \\
\hline $\begin{array}{l}\text { Produção e Dis- } \\
\text { trib. Eletricid., Gás } \\
\text { e Água }\end{array}$ & 85 & 81 & & & 81 & & & & 77 & 58 & 38 & 42 & 27 & 46 & 27 & & \\
\hline $\begin{array}{l}\text { Autom., Instrum. } \\
\text { e Projetos }\end{array}$ & & 82 & & 91 & 82 & 82 & 64 & 82 & 73 & & & 36 & & 18 & & 18 & \\
\hline Tecnol. Inform. & 81 & 81 & 77 & & & 73 & 85 & & & 58 & & 31 & 23 & & 19 & & 8 \\
\hline $\begin{array}{l}\text { Cultura, Lazer e } \\
\text { Turismo }\end{array}$ & & 100 & 100 & 100 & & & 100 & & & 100 & 50 & 50 & & & & 50 & \\
\hline $\begin{array}{l}\text { Organism. Inter- } \\
\text { nac. e Outras Ins- } \\
\text { tit. Extraterrit. }\end{array}$ & 100 & 100 & & & 67 & & & 67 & 58 & 67 & & 25 & 33 & & & & \\
\hline Construção & 83 & & & & & 79 & & 68 & & & & 42 & & & & 19 & 19 \\
\hline $\begin{array}{c}\text { Outros Serviços } \\
\text { Coletivos, Sociais } \\
\text { e Pessoais }\end{array}$ & 83 & & 75 & & & & 66 & & & & 22 & & 22 & & & 13 & \\
\hline Educação & & 76 & 70 & 70 & & & & & & & 23 & & 22 & & & 16 & \\
\hline $\begin{array}{l}\text { Admin. Pública, } \\
\text { Defesa e Seguri- } \\
\text { dade Social }\end{array}$ & & & 74 & 68 & & & & & & & 27 & & 22 & & & 15 & \\
\hline Comun. & & & & & & 67 & & & & & & 22 & & & 22 & & 6 \\
\hline $\begin{array}{c}\text { Saúde e Serviços } \\
\text { Sociais }\end{array}$ & & & & & 68 & & & & 63 & & 35 & & & & & & \\
\hline Não Ident. & & & & & & & & & & & & 20 & & & 15 & 14 & \\
\hline $\begin{array}{l}\text { Comércio, Repa- } \\
\text { ração de Veículo } \\
\text { Automotor, Ob- } \\
\text { jetos Pessoais e } \\
\text { Domésticos }\end{array}$ & 83 & & & & & 79 & 66 & & & & & & & & & & \\
\hline $\begin{array}{l}\text { Atividade Imobi- } \\
\text { liária, Aluguéis e } \\
\text { Serviços Presta- } \\
\text { dos a Empresas }\end{array}$ & & & & & & & & & & & & & & & & & \\
\hline \multicolumn{18}{|c|}{$\begin{array}{l}\text { *VT = Vale Transporte. } \mathrm{CM}=\text { Convênio Médico. EO = E-mail da Organização. E = Estacionamento. EM = Exame Médico } \\
\text { Periódico. } \mathrm{AS}=\text { Adiantamento Salarial. } \mathrm{CN}=\text { Confraternização de Natal. } \mathrm{RR}=\text { Refeitório/Restaurante. } \mathrm{MT}=\mathrm{Médico} \text { do } \\
\text { Trabalho. } \mathrm{CF}=\text { Convênio com Farmácias. } \mathrm{C}=\text { Creche. } \mathrm{A}=\text { Automóvel. } \mathrm{AP}=\text { Atendimento Psicológico. } \mathrm{CC}=\text { Cooperativa } \\
\text { de Crédito. } \mathrm{AM}=\text { Auxílio Medicamento. } \mathrm{AJ}=\text { Assistência Jurídica. } \mathrm{AC}=\text { Aluguel de Casa. } \mathrm{BS}=\text { Benefícios Sociais. }\end{array}$} \\
\hline
\end{tabular}

Com base na Tabela 6, verifica-se que, entre os dez BS mais recorrentes e os sete menos disponíveis, quatro grandes setores de atividades apresentam oferta do BS acima da média dos demais. São eles: indústrias extrativas (acima da média em 15 BS), indústrias de transformação (acima da média em 15 BS), agricultura, pecuária, silvicultura e exploração florestal (acima da média em 15 BS) e transporte, armazenagem e comunicações (acima da média em 13 BS).

Por outro lado, oito outros setores obtiveram destaque em seis ou menos BS, a saber: 
construção (acima da média em seis BS), outros serviços coletivos, sociais e pessoais (acima da média em seis BS), educação (acima da média em seis BS), administração pública, defesa e seguridade social (acima da média em cinco BS), comunicação (acima da média em quatro BS), saúde e serviços sociais (acima da média em três BS), comércio, reparação de veículos automotores, objetos pessoais e domésticos (acima da média em três BS) e atividades imobiliárias, aluguéis e serviços prestados às empresas (acima da média em nenhum BS).

\section{CONSIDERAÇÕES FINAIS}

A oferta de BS, na estrutura da legislação trabalhista existente no Brasil, pode ser uma estratégia de gestão de talentos interessante e decisiva na atração e retenção de pessoas, pois na maioria dos casos não leva a ônus adicionais em termos de tributação. O presente estudo pesquisou 35 diferentes tipos de BS com 1.781 pessoas, em todas as regiões do Brasil, abrangendo diferentes tipos de BS praticados, o que possibilitou estratificar dez deles entre os mais recorrentes e sete deles entre os menos frequentes.

Constata-se, ainda que sem a pretensão de generalização estatística, a despeito do elevado número de respostas, que trabalhar em empresa pública ou empresa de capital misto, que, juntas, na amostragem, representam pouco mais de $3 \%$, garante acesso à maioria dos $\mathrm{BS}$, sejam eles os dez mais presentes ou mesmo os sete menos frequentes. Além disso, trabalhar nas regiões Nordeste e Norte, que, juntas, foram representadas por apenas $2,5 \%$ dos respondentes, possibilita elevada chance de ter acesso a inúmeros BS, enquanto na região Sudeste, representada por mais de $87 \%$ dos respondentes, destacou-se na oferta de apenas um BS, este ainda dentro dos menos disponíveis. Pode-se supor que isso se deve à maior oferta de executivos nas regiões com mais respondentes.

Foi na posição hierárquica média que se verificaram as maiores presenças de oferta de BS (13 dos 17 BS estudados em detalhes estão ofertados a esse público, com apenas quatro para pessoal de posição hierárquica alta). Fica evidente que BS estão menos disponíveis às posições mais baixas das organizações, talvez pelo fato de essas posições serem de maior facilidade de reposição na realidade de oportunidades de empregos no Brasil.

Já quanto à escolaridade, fica evidenciado que quanto maior a escolaridade, maior o acesso aos BS, pois, em apenas um dos 17 BS estudados em detalhes, aparece a escolaridade graduação como destaque no acesso ao BS. Os demais 16 BS estão disponíveis predominantemente para profissionais com maior escolaridade. Destaque-se que os setores da atividade educação e saúde, cotidianamente ditos como essenciais, não recebem a atenção devida em termos de oferta de BS com forma de atração/retenção de talentos.

A concessão de BS aos trabalhadores tem componentes estratégicos importantes para as organizações. Tais BS podem prestar-se tanto a criar diferenciais que tornem a organização mais atrativa (e potencializem a maior retenção de talentos) quanto a viabilizar melhores condições de trabalho, na medida em que alguns BS, apesar de representarem mais gastos, não implicam elevação da carga tributária. Equivale a dizer que, em algumas situações, a disponibilização de BS significa ganhos reais para os trabalhadores, a despeito de não implicar aumentos salariais, sem implicar elevação abrupta dos gastos com pessoal, quando os BS estão livres de encargos que incidem diretamente na folha de pagamentos, o que ocorre com o aumento real de salário/vencimentos.

Com este trabalho, que procurou analisar a presença da oferta de BS pelas organizações laborais, constatou-se que, na maioria dos casos, as organizações limitam-se a oferecer BS básicos ou apenas aqueles previstos em convenção coletiva de trabalho. Entre os dez BS mais ofertados, pelo menos cinco deles (convênio médico, exame médico periódico, médico do trabalho, 
licença sem remuneração e vale transporte) são previstos em legislação específica. Os outros cinco (e-mail, estacionamento, plano de carreira, confraternização de Natal e refeitório/restaurante) implicam algum investimento.

O estudo oferece implicações práticas para as organizações e seus gestores, pois a constatação de que existem parcos atrativos à profissão, pelo menos no que tange à oferta de benefícios diferenciais, pode desvendar uma oportunidade: elevar a oferta de BS em suas organizações como forma de captar/reter os melhores talentos. Os próprios dados revelam quais poderiam ser os BS mais atrativos pelo trade off entre as diversas alternativas de BS, buscando os que possam ser os mais diferenciadores e que impliquem o menor investimento.

Este artigo possui limitações, tanto no que se refere à fragilidade teórica encontrada na revisão da literatura sobre o objeto e à inexistência de estudos específicos, como no tratamento dos dados para a concepção dos resultados, o que por si caracteriza-se como uma oportunidade para que novos estudos sejam realizados. Foram pesquisados quais BS são oferecidos pelas organizações aos seus profissionais e a que setores de atividade econômica eles se destinam, mas do ponto de vista dos empregados. A pesquisa, assim, está centrada nos profissionais, e não em como as corporações implementam tais políticas de benefícios. Sugere-se, dessa forma, um estudo futuro com os empregadores, mapeando como acionam os benefícios em suas políticas salariais. Portanto, a continuidade dos estudos tanto teóricos quanto empíricos acerca do tema é necessária e fundamental.

Ainda como sugestão para novos estudos, deve-se comparar setores da economia para que se possa estabelecer se existem, de fato, diferenças que possam levar a crer que está havendo precariedade na oferta de BS a algum setor. Sugere-se ainda discutir a relação entre os BS facultativos e compulsórios, pois os resultados deste estudo apontam que alguns BS compulsórios não estão presentes em todas as organizações. Esse tópico poderá ser investigado por meio de uma entrevista em profundidade com os gestores de empresas representativas dos setores identificados aqui. A continuidade de estudos relativos ao tema é de suma importância para o desenvolvimento desse tipo de atuação organizacional, bem como para a valorização dos profissionais na realidade brasileira.

A continuidade do estudo também poderia enveredar por métodos de caráter qualitativo, com a realização de entrevista em profundidade com os gestores das organizações, procurando identificar se existe preocupação ou importância com a satisfação das pessoas em sua atuação profissional; e se está clara na definição de missão das organizações a preocupação com o capital humano/intelectual.

\section{REFERÊNCIAS}

AMARAL, C. T. et al. Análise das demonstrações contábeis e indicadores sociais da Companhia Estadual de Energia Elétrica (CEEE-GT). ReFAE - Revista da Faculdade de Administração e Economia, v. 4, n. 2, p. 2-24, 2013.

APPEL, Z. M.; PUCCI, V. R. Comportamento pessoal versus comportamento organizacional. Psicol. Am. Lat., México, n. 9, abr. 2007.

ARBACHE, J. S. Uma introdução aos salários indiretos no Brasil. In: Encontro Nacional de Estudos do Trabalho, 1995, São Paulo. Anais... São Paulo, 28-29 set. 1995. p. 1.297-1.322.

BIERNACKI, P.; WALDORF, D. Snowball sampling: problems and techiniques of chain referral sampling. Sociological Methods \& Research, v. 10, n. 2, p. 141-163, 1981.

BRASIL. Secretaria de Assuntos Estratégicos. Caderno 4: classe média e emprego assalariado. 
Vozes da nova classe média. Brasília: SAR, ago. 2013.

CLARO, J. A. C. S. Theoretical and empirical evolution in corporate hospitality. e-JESS - Electronic Journal of Economic Sociology Studies, v. 3, n. 3, p. 266-278, 2013.

; PROFETA, R. A. Programas de benefícios sociais para docentes no ensino superior brasileiro como forma de reter talentos: um estudo exploratório. Avaliação, v. 20, n. 1, p. 189223, 2015.

COSTA, V. M. G.; CUNHA, J. C. A universidade e a capacitação tecnológica das empresas. RAC Revista de Administração Contemporânea, v. 5, n. 1, p. 61-81, 2001.

DUNZER, G. A.; MELO, E. M. P.; MELO, J. S. C. Desafios de atração e retenção de talentos - estudo de caso da Petrobras. In: Encontro da Associação Nacional de Pós-Graduação e Pesquisa em Administração, 32., 2008, Rio de Janeiro. Anais... Rio de Janeiro: ANPAD, set. 2008.

GHENO, R.; BERLITZ, J. Remuneração estratégica e pacote de benefícios: um estudo de caso aplicado ao nível operacional de uma multinacional. Revista de Administração da UFSM, v. 4, n. 1, p. 268-287, 2011.

GOMES, V.; CASTRO, E. R. Trabalhadores da Albras e sua organização política. Novos Cadernos NAEA, v. 7, n. 1, p. 123-154, jun. 2004.

HAIR JR., J. F. et al. Fundamentos de métodos de pesquisa em administração. Tradução Lene Belon Ribeiro. Porto Alegre: Bookman, 2005.

IBGE. Instituto Brasileiro de Geografia e Estatística. Classificação Nacional de Atividades Econômicas - CNAE, 2013. Disponível em: <http://www.ibge.gov.br/home/estatistica/economia/ classificacoes/cnae2.0/defaulttab.shtm>. Acesso em: 10 jun. 2013.

LEONARDO, J. M. A. A guerra do sucesso pelos talentos humanos. Revista Produção, v. 12, n. 2, p. 42-53, 2002.

MARQUES, S. V. D.; MARTINS, G. DE B.; CRUZ SOBRINHO, O. Saúde, trabalho e subjetividade: absenteísmo-doença de trabalhadores em uma universidade pública. Cadernos EBAPE.BR, v. 9, Edição Especial, p. 668-680, 2011.

MEDEIROS, C. A. F. et al. Comprometimento organizacional: o estado da arte da pesquisa no Brasil. RAC - Revista de Administração Contemporânea, v. 7, n. 4, p. 187-209, dez. 2003.

MOURÃO, A. N. M.; ALMEIDA, M. E.; AMARAL, E. F. L. Seguro-desemprego e formalidade no mercado de trabalho brasileiro. R. Bras. Est. Pop., v. 30, n. 1, p. 251-270, 2013.

ORO, I. M.; RENNER, S.; BRAUN, M. Informações de natureza socioambiental: análise dos balanços sociais das empresas integrantes do Índice de Sustentabilidade Empresarial da BM\&FBOVESPA. Revista de Administração da UFSM, v. 6, Edição Especial, p. 247-262, 2013.

PERES, M. A. O pacto de benefícios utilizados pelas empresas como atrativo aos funcionários: um estudo de caso no ramo financeiro. 72 f. 2011. Monografia (Especialização)-Universidade Federal do Paraná, Curitiba, 2011.

PIZOLOTTO, M. F. Políticas de benefícios sociais em empresas do setor metal-mecânico do Rio 
Grande do Sul. 2000. Dissertação (Mestrado em Administração)-Universidade Federal do Rio Grande do Sul, Porto Alegre, 2000.

PUENTE-PALACIOS, K. E.; PACHECO, É. A.; SEVERINO, A. F. Clima organizacional e estresse em equipes de trabalho. Revista Psicologia: Organizações e Trabalho, v. 13, n. 1, p. 37-48, 2013.

RATTNER, H. Benefícios e motivação no trabalho. RAE-Revista de Administração de Empresas, v. 6, n. 19, p. 14-40, 1966.

ROSALEM, V.; SANTOS, A. C. DOS. Globalização social: desafio do século XXI. Revista de Administração da UFSM, v. 3, n. 2, p. 183-190, 2010.

SILVA, L. B. A Gestão de pessoas e o sistema de reconhecimento e recompensa em Organizações Não Governamentais. In: Encontro da Associação Nacional de Pós-Graduação e Pesquisa em Administração, 37., 2013, Rio de Janeiro. Anais... Rio de Janeiro: ANPAD, 9 set. 2013.

THEOTÔNIO, K. S.; REIS NETO, M. T.; LOPES, S. A. A remuneração no Brasil: uma análise segundo os aspectos legais. In: Encontro da Associação Nacional de Pós-Graduação e Pesquisa em Administração, 37., 2013, Rio de Janeiro. Anais... Rio de Janeiro: ANPAD, 9 set. 2013.

TINOCO, J. E. P. et al. Estudo sobre a carga tributária de empresas brasileiras através da demonstração do valor adicionado (DVA) - período de 2005 a 2007. Revista Ciências Administrativas, v. 17, n. 1, p. 84-111, 2011.

VALADÃO JR., V. M.; RODRIGUES, H. G. Competências na pós-graduação: o olhar dos egressos. Administração: Ensino e Pesquisa, v. 13, n. 2, p. 325-354, 2012. 